HStud 24 (2010)2, 293-306 DOI: 10.1556/HStud.24.2010.2.9

\title{
INTERNET AND LITERATURE - SOME RECENT HUNGARIAN EXAMPLES
}

\author{
GYÖRGY C. KÁLMÁN \\ Institute of Literary Studies, HAS, Budapest \\ Hungary
}

\begin{abstract}
Digital storage and retrieval of texts has been in the focus of an entire branch of contemporary literary studies. Literary texts online meant a new step, allowing readers to access (and editors to build and modify) the corpus in a radically new way, via the Internet. A recent development, however, the era of the network (with its "community sites" and all the different interactive communications between users) raises quite new issues. In addition to problems of archiving, accessibility and connectibility, the issues of literature produced and received on the Internet came to the fore, and deserve interest and theoretical reflection in their own right. In this study, some cases from the Hungarian internet scene concerning the temporality, authorial position, collective production, etc. are described, in order to call for a more systematic and thorough survey of these phenomena in general.
\end{abstract}

Keywords: Internet, literature, Hungarian literature, temporality, Facebook, archiving, online, network

\section{Online Archives}

Much of the discourse in Hungarian professional circles concerning the relationship between the Internet and literature is centered around archiving; i.e., around the issues of preserving, structuring and retrieving literary texts (which, of course, have been produced and published before gaining their position in the field of internet communication). In present day Hungarian literary studies, since as early as the 1980s there has been a growing interest in databases and critical editions of literary texts (especially poetry), both theoretically and practically. Later the problem of Internet publication of literary studies and even a huge handbook of Hungarian literature on the web became fairly well known among literary scholars.

This orientation is largely due to the work of an excellent and influential literary scholar, Iván Horváth, who first produced a large (and, to my knowledge, complete) database of old Hungarian poetry ${ }^{1}$ that allows the reader to retrieve and 
classify, according to several features, any of the poems written in Hungarian before 1601 (and published before 1701). The user of this database can search, for instance, types of lines and stanzas, genres, metrical schemes, rhymes, religious content (if any), and so on - or a combination of these criteria, and, of course, free text search is also available. Following the completion of this monumental work, Horváth, together with his colleagues and students, turned to the critical editions of some major Hungarian writers; first the Renaissance poet Bálint Balassi, ${ }^{2}$ and later a work still in progress, all the poetic and other works of Attila József, one of the most significant Hungarian poets of the first part of the 20th century. ${ }^{3}$ Since the late 1990s, several students of Horváth have produced a number of online critical editions. ${ }^{4}$

There are at least two more important bordering areas that have become foci of Horváth's interest: first, the "computational" production of poetry, starting from the mechanical versification machines of early Modern Germany to the computational experiments (variations, permutations, etc.) of the Oulipo Group and the Neo-Avant-garde. As computing technologies develop, one may have a more precise and clear way of understanding, reproducing and expanding these practices. Second, the course of editing a huge monograph on the history of Hungarian literature, with contributions of numerous authors, raised the issue of reformulating and reorganizing this "history" and making the text, in a way, interactive - that is, inducing and producing a "stochastic" reading of the literary historical text, thus offering the reader the possibility to make a literary history of her own. (This problem related to an element of Horváth's theory of text editing, namely that in cases in which several rival textual variations exist effectively one must make a decision on a random basis. $)^{5}$

This pioneering work deserves nothing but respect; however, some later developments may reveal its shortcomings - or, rather, it now seems that this conception of the relationship between the internet and literature should be complemented. It is highly telling that what is called "online" in the English translations of Horváth's enterprises is, in Hungarian, "network" - but, in fact, "online" is the suitable expression. "Network" suggests that, in addition to his/her connection to the database or the critical edition, the reader will establish connections to other readers or, for that matter, the editor(s) of the texts in question. However, these online editions can be very easily replaced by a CD-ROM or a DVD (or any other vehicle of information), and they do not even have to be online; no reader-reader or reader-editor communication is possible, except perhaps for the very limited feedback via email to the editors or (sometimes) forums for comments.

Horváth and his disciples have a detailed and subtle conception of what a text is and how it should be digitally stored and processed. What they have in mind is clearly a text as a manuscript and/or a publication, its copies, variations, fragments and distortions, independent of its visual (calligraphic, typographic, etc.) 
appearance. Paratextual and contextual features are more or less excluded. They may "intrude" (along with a very limited amount and kind of interpretation) only inasmuch as they contribute to the precise archivation of the text. The texts in question are ready, finished, completed; thus archived, they are not open any more for any alteration, modification, or emendation, except perhaps for the editor: the archive is not at all interactive, it has a privileged position.

\section{Online and Network}

This archive (critical edition, database) belongs to the "online" period of the era of the Internet, as opposed to the "network" era in which we are living now. The reader has (free or prepaid) access to the corpus, wherever he/she happens to be; he/she does not have to store the whole material on his/her bookshelf, and still may access the data he/she needs whenever and wherever he/she would like. And, of course, an archive like this is incommensurably faster and more reliable than any of those in the "book" period. It offers far more opportunity for sophisticated retrieval, and it is much easier to handle in general.

A private initiative was launched very early, at the beginning of the Internet era in Hungary, with the intention of digitalizing - in a rather chaotic, capricious, random way, relying merely on the taste of the volunteering contributors - major Hungarian literary texts. It was then taken over by the National Széchényi Library and went through substantial technical developments. It now works as the digital part of the library itself. Another official corpus is produced by the Digital Literary Academy, formed after the enactment of a law ensuring the digitalization of all the texts of literary Kossuth Prize winners. (It is the highest official, state adjudicated award for writers and other people of culture and - earlier - science.) DIA is responsible for producing and maintaining possibly the whole work of the award winning writers, along with a bibliography and a selection of critical works.

The "network" period, however, requires a verily interactive usage of the text(s collected). An opening must be given to the reader to comment on the text and to cooperate with other readers, as well as with the "service" (the editors and administrators of the text). There may be graduation in access, i.e., some professionals might be given more rights than others, and there can be moderation with clear rules; but, in sum, a lively discussion may arise from the different and contradicting interpretations and comments in general. The archive itself, though, should be kept intact (and sometimes modified, according to new findings, perhaps the fruits of the discussions themselves, by the editor); but anyone can, individually or to-

gether with other users, produce a special modification: an anthology of poetry of five line stanzas, another of a specific rhyme pattern, etc. Anyone may publish his 
or her own text(s) connected in some fashion to the text(s) of the archive. This is a version of what Siegfried J. Schmidt once called "the erotic of interpretation" - a continuous generation of texts on texts, without any prior theoretical consideration; this is both a source and a reduplication of what is called literary life, and it is in fact a part of literary life.

This insight must have been in the background of what was designed to be a new history of Hungarian literature. This project, then, can be considered as belonging to the "network" era. Unfortunately, it does not really work, despite the expectations and previous declarations. The work (tellingly entitled "Histories of Hungarian Literature") contains too many chapters, the formulations are too professional, and it is too voluminous a text to manage anyway. The idea is that of a network - the reader is invited to make a history of his or her own, and to discuss this history with other users. The policy of the site, however (which unfortunately is moved from time to time, and therefore it is not easily available - search "Neospenót" or "Villanyspenót" to find it), is perhaps overly cautious: for one to comment one must not only register, but comments must be approved by the editor and an editorial group, and they are published only after a corporal decision.

Another work in progress is worthy of mention in this context, an undertaking similar in vein but independent of Horváth's school: the critical edition of the Hungarian translation(s) of Joyce's Ulysses. This work, soon to be published on the Internet (http://www.mjjm.hu/), edited by András Kappanyos and co-edited by Gábor Zoltán Kiss, Marianna Gula and Dávid Szolláth, compares the two existing translations with each other as well as with the English original. It emends and corrects them and offers commentary on the more delicate points, including discussion of possible variations. Readers may, after registration, send their comments and discuss the solutions. It represents an excellent work, though it is certainly not for the widest reading public.

Roughly, the conception (both of Horváth and Kappanyos) is to produce an archive (or a set of texts) and make it open for readers; the central text may generate discussions, and the readers will then create a network around this core element. No doubt, this could be one way to make literature (in a broad sense, including literary studies, criticism and any interpretation of literature whatsoever) interactive. There has been also another form, namely mailing lists and SIGs ("Special Interest Groups, which are normally focused on a mutual interest or shared characteristic of a subset of members of the organization" - Wikipedia). These virtual communities are formed to discuss various problems and different issues in literature (or literary history) among several others. In its original, e-mail based form, the group system has some shortcomings. It is quite difficult to search (old, forgotten topics may turn up again and again), the results are not fixed on any independent site, it is not easy to form a smaller cluster, it is not possible to publish one's profile (introducing one's interests, works or personal details), just to name 
a few of the complications that arise. Some virtual communities, however, while preserving the mailing list component, manage to organize a stable homepage site where important and permanent elements are stored. ${ }^{6}$

\section{Literature on the Net}

Networking may pose new questions for the student of literature not raised by online reading. First, not only is it possible to read (and/or rearrange, interpret, and comment on) previously archived texts in hyperspace, but one may also come across texts in the making; a reader may have opportunities to comment on a work underway. Second, it is likely that he or she will communicate with other readers of the same text, or she may call the attention of others to a particular text (completed or in progress). And, third, new genres can be found on the net, or texts with special borderline positions - between text and image, between literary and other discourses. There will be quite special types of paratext, authorial positions, and contexts.

\section{Blogs}

To clarify the meaning and types of blogs is far beyond the scope of this paper. Suffice it to say that there must be a subset of blogs, among the tens or even hundreds of thousands of them on the Internet today, which can be characterized as being close to what are referred to as literary texts. There is, furthermore, an interesting version of blogs where earlier literary works are posted (for instance, on a daily basis), the favorites of the blogger; a sort of ever growing private anthology. If comments are allowed, this may be instructive as far as the (re)interpretations of works more or less broadly familiar are concerned, or they may reflect on the ways the choice is made, etc. There are also blogs of various types about literature, including subjective accounts of literary texts, occasional digressions concerning literary experiences, etc.

Some blogs may be regarded as literature partly due to their stylistic features, partly to their self-classification, partly to their reception (classifying them as literary blogs), and so on. If it is true that it is impossible (and perhaps pointless) to circumscribe literature, in its "traditional," printed (or manuscript) form, the same task would be considerably more complex in the case of blogs, where even the well-established institutions of literature are absent. The concepts of authorship, publication, paratextual information, reading public and interpretive communities gain new meanings. 
To eliminate these uncertainties and canalize these disturbing features into a course of a long tradition, blogs are sometimes presented in printed (book) form. They then take the form of a diary, a novel, a volume of poetry - something with which the reader is already familiar. However, this is a highly doubtful operation. First, omitting the comments constitutes a clear truncation by which the text may lose much of its interest, not only because it is a loss in paratexts but also because comments may influence the (next) posts and the whole interpretive context of the text. The omission gets rid of the whole "community" of readers who interacted with the creation of the work. (In footnotes, however, the comments attached to the post may be preserved and reproduced.) Second, the temporality of the blog is lost. A printed text is unable to reproduce the fact that the blogger may post a text three or four times a day, may then take a week break, and then return to a rhythm of daily posting. The blogger may post at a hectic pace for a time, and then fall silent, ignore, or discuss the comments. Comments may be posted much later than the original post, or there may be prompt reactions.

\section{Temporality: Prose Fiction}

This second peculiarity of the blog is impossible to reproduce; the reader's experience will be very different reading the blog online, in real time, than facing it in its offline reproduction. It is impossible to ask the reader of the offline version to wait a few days before passing to the next post; the event of posting is a dramatic one, to which the temporal dimension is very closely attached; they are unique, single happenings that can be experienced only in their immediate occurrences, like a dramatic action in a theater (the big difference being that a piece of theater is - more frequently than not - designed to be staged, with all its stage and other directions; on the other hand, a theater performance can be more or less precisely recorded - on film or video - , preserving the time element; but it would be absurd to make a months-long video about an evolving blog, with its pauses, accelerations, and retardations).

Temporality appears in several shapes in online (or network) literature. For instance, presenting a work in small doses, in regular intervals, in a literary magazine, is a tradition dating back some two centuries, or perhaps more. Several novels were first published in even portions. In some cases they were completed prior to this dismemberment, in others they were in fact being written during the intervals. In this respect, some forms which seem to belong to what one may label Internet-based literary communication follow, in fact, a very traditional scheme: the author publishes a text, as a whole or in discrete portions, which then is read by the readers - this being the case even if the site of publication is the Internet (blog, 
"community site" or anything else). Temporality, in this respect, does not count too much.

However, even in early variants of such works of literature, in the 19th century or before, the chance for reader-writer interaction was present: authors could (and sometimes did) change the course of events represented, taking into account their readers' reactions. Changes were made to the initial conception, due to the pressures of editors, readers, censorship, or the social-political environment. In the age of Internet, and especially in the network era, however, these influential factors may be public, overtly seen and discussed by those within the network, so that the temporality of presenting the work is supplemented with the temporality of the readers' comments.

An outstanding prose writer, Gergely Péterfy, for instance, created a page on Facebook for his tale-novel, "Pannon Mese" ("Pannonian Tale" - Pannonia being the Latin name of the ancient Roman territories, partly in Hungary, west of the Danube). It is a page following the publication, every Sunday, of new chapters of the work. The Facebook page hosts the reflections of both the author and his readers, and Péterfy even explicitly calls on the "fans" (the page has more than 1,000 of them) to comment on issues bearing on the characters, plot, intelligibility, etc. The offline (book) publication is in preparation, and allegedly the final version will take into consideration the comments made on Facebook. Furthermore, some characters of the novel have their own profiles on Facebook, so that they too can have "friends."

\section{Temporality: Lyrical Poetry Offline}

Temporality of narrative, in this sense (that is, episodic publication, with intermissions), seems to be, then, a conventional phenomenon, even if the Internet opens new and interesting prospects. It is far easier, for instance, to overcome the difficulties of anachrony. In a print periodical it is not advisable to invert time patterns or change time levels, because this may hinder the perspicuity of the plot. On the internet this is somewhat less dangerous. And after all, a narrative evolves in time, so presenting this process by picturing the time passing seems to fit what is presented.

Lyrical poetry, on the other hand, has quite a different relation to the element of time. There are, to be sure, a number of lyrical poetic works with narrative elements, and one could even suggest that any lyrical work can be read as a sort of dramatic monologue, a sort of speech recited in a certain situation, in a scene, as it were. However, it may well be the general impression that works of lyrical poetry are beyond and outside of time. What impressions do recitations of poems with pauses or sudden changes of pace actually make? Impressions of the (imagined) 
temporal progress of writing the poem itself? Or the tempo of recalling the text? Or the weight of the thoughts? Reading the poem, however, can give only visual signals of the time passing, such as the blank spaces of Mallarmé or the stanzas as articulations, or, again, breaking the lines, or certain punctuation marks $(-, \ldots$, , etc.). But note that all these indicators serve to block (or slow down) reading (or reading aloud) the text - nothing will make the reader accelerate, jump or "jabber."

Representing the passage of time in a poem (or rather, the time of the poem) may have a humorous effect. For instance, take Dezső Tandori's poem, The Sonnet (1973):

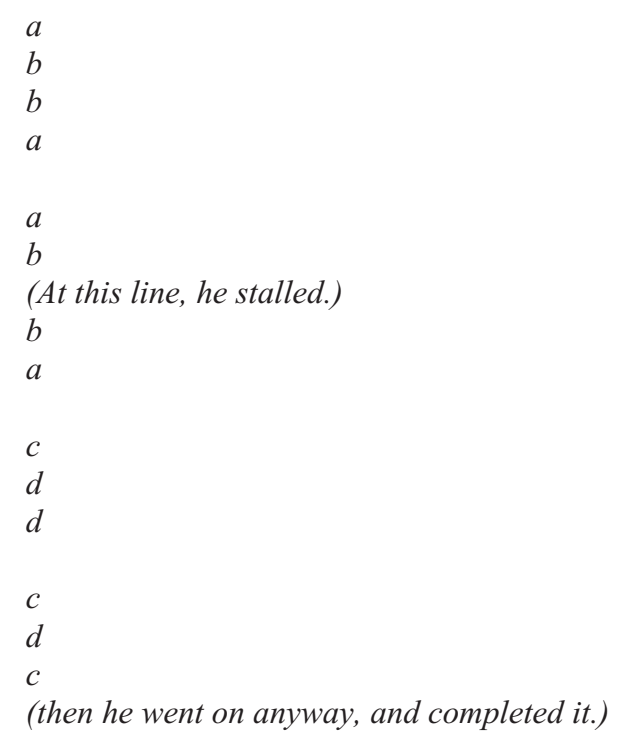

Here the lyrical is transformed into a narrative: the writing of the poem itself has a history, and this can be built into the poem itself, and also into reading of the poem. And, ironically, the "purely" lyrical element, which is confronted here with the narrative of writing/reading the poem, is nothing but a "pure" series of letters symbolizing the rhyme pattern.

\section{Temporality: Lyrical Poetry Online}

In addition to these phenomena, where breaks, stalls, stops are only momentary and left to the reader (in other words, in addition to conventions realized in the medium of the printed text), there is now in the age of the Internet a new possibility to utilize the temporal aspects of poetry. The "dramatic" nature of presenting 
the text in portions, the unique nature of following (in real time) the online publication of the text, mentioned above in connection with the event of posting chapters of a narrative, may be part of online lyrical poetry as well. What happens in these - rare-occasions represents an instance of written literature, but poem here is drawn near to the genre of performed drama: it is prescribed how the text should evolve in the readers' time, their passing the time is controlled, and even the process itself may be suspended or cancelled.

Mari Falcsik, a well known poetess (http://www.freewebs.com/falcsikmari/, http://falcsikmari.honlapepito.hu/), in early 2010, published two lines in English on the Facebook "News Feed" page (available for all her "friends"), evidently (part of) a poem, without any explanation. A few minutes later she added two lines in Hungarian, apparently the translation of the English (or vice versa). Then a few minutes later two more lines in English, follow by two in Hungarian, and so on and so forth, with 5-10 minute intervals, until the end of the poem. Those who were "present" were able to comment on the posts, express whether or not they "liked" them, and, paralleling to this publication, the same text(s) appeared on Twitter.

Experiencing the act of creation in real time was an extraordinary incident. Not because of the poem itself (it was, in fact, the act of translation of Falcsik's own poem into English), but because the reader was able to feel like a participant in a dramatic event. Something developed before the reader's very eyes, so that something (a text) which normally is as a poem gained a temporary dimension, becoming an event. The poem then could be read later, starting from Falcsik's older posts on the News Feed, but then what is found is merely a text in small portions, and the reader misses the experiment of the poem evolving in time.

\section{Authorship on the Internet}

But who is the actor directing the reader and controlling his or her reading? Whose is the "power" in the Internet communication of literature in the cases mentioned above?

Even in the case of offline texts, that is, in the more conventional, traditional forms of literary communication, the position of the text has long been discussed, and the concept of authorship always entails assumptions and hypotheses, rather than positive knowledge. The "real" author may be regarded as dead, can be parenthesized, or can be seen as palpable, responsible, existing in real life, etc., depending on conventions, erudition, or concept of literature. The internet, however, produces a more complex situation: it opens possibilities for the author to play new games with his or her identity, just as in traditional literary communication it is a certain set of texts by which (unreliable) information is gained concern- 
ing the ("real") person belonging to the authorial name, so in the medium of world wide web these texts will easily and quickly proliferate, and we find ourselves rapidly enmeshed in the net of the texts encompassing that name.

This year (2010), Margaret Attwood published an essay in her blog of The New York Review of Books on her experiences with Twitter. When she started using Twitter, there had already been two persons using the same name ("Margaret Attwood"), and she received several letters asking if it was really her, since one can never be quite sure who one is communicating with through the medium of the Internet. Politicians making use of Internet marketing and propaganda do not (or perhaps only in the rarest cases) write their own posts. Rather, they have a group of PR experts working for them. The strategies underlying the processes of building and using a persona (an imagined identity which can be hypothesized or inferred) merit a separate study. This is of interest in this context not only because of literary (aesthetic) reasons (or, for that matter, political, business, etc. reasons). On the "community sites" people demonstrate certain behaviors: some are hectic and aggressive, others are reserved, some tend to comment on every possible post, and, of course, there are several forms of conduct, not to speak of habits of posting music and pictures, of the abundance or narrowness of the personal network, that is, of non-textual peculiarities. Some are known as writers, and they are positioned accordingly in the set of information mediated by the world wide web, and there are "no name" friends (either literally, using a pseudonym, or because their

name is not familiar) who nonetheless begin to be taken into account as creators of some aesthetic experience.

\section{Collectivity}

In 2000, the Magvető publishing house and Fókusz Online (the Internet site of one of the biggest bookshops in Hungary) invited applications for the composition of a novel. Several participants published one part per week, and on the basis of the decision of a jury six of them were chosen to continue. Finally the work of a certain Jake Smiles (a pseudonym, of course) was announced as winner. His (her?) text was very soon published in book form, with considerable success. Jake Smiles is well informed in the world of the web, and he very consciously uses the instruments available (and his/her knowledge of the media itself is evident in the few interviews given by him/her).

The work has some traits of collectivity, inasmuch as the text was modified (or could have been modified) in accordance with the comments of the readers following its production. However, with the heyday of the "community sites" in the past couple of years, collectivity appears in quite a new situation. Readers of the text being composed are there not specifically to observe or comment on the pro- 
cess, they just happen to be present. The pages serve social life and information exchange. The users may contact acquaintances, either close or casual, they can chat in public or privately, they can share news or their favorite music, pictures, links - and the acquaintances then can reflect on all these manifestations or simply express whether or not they "like" them. It is a great opportunity to have a social network and get acquainted with one another's tastes, and one is absolutely free to do so. One may refrain from entering the page for months, if one so chooses, or just merge into mere observation without commenting any post, music, picture, or link. And, of course, one can be present day and night, looking for new friends and commenting on whatever happens to grab one's interest.

This also means that the chances of encountering literary works are much greater than if somebody were simply to surf websites. Sooner or later a friend (or a friend of a friend) may suggest a book (or a poem, novel, short story) to read, advise to join some "fan club" of writers, publishing houses, etc., or friends may make an effort to write a poem or a short story themselves, and references to and citations from literary works eventually will appear in the flow of posts. This is not necessarily "high" or valuable or "classical" literature, but when people all around the world have less and less interest in written literature - and, accordingly, there are less and less reader-work encounters - "community websites" may contribute to restore the position of literature. Thus not only creation may sometimes (if rarely) be of a collective nature, but - more importantly - the consumption of the work is very often a collective act of the readers, with interpretations and their discussions, sometimes with direct access to the writer (and his authorial interpretations).

As to the cooperative creation of writers of literature, a recent example is a short poem by two first-rate poets, Ágnes Rapai (http://legeza.oszk.hu/ Rapai_Agnes/index.html) and Lóránt K. Kabai (http://kkl.mentha.hu/ - he writes his name "k. kabai lóránt”, without capitals). Rapai sent a line to k. kabai's wall; k. kabai added another line, then sent it back. It was Rapai's turn again, and k. kabai wrote the fourth line... Those who were "friends" of both could follow the poem as it developed. Others, who knew only one of them, could read the whole poem after it was finished, on both authors' walls.

Another case of (a limited version of) collectivity happened when a lesser known poet, Gyula Hodossy, asked his Facebook "friends" (and the members of a group devoted to Hungarian net literature) to help him edit his new volume - that is, after the Internet publication of his work on Facebook, the readers were invited to form the final contents of the would-be book and the order of the text, and also to comment on each poem.

Another type of collectivity (in a very limited sense, again) is when a writer publishes his or her work in portions on the Internet (in this case, Facebook, again), making use of the comments attached to the work in progress and even in- 
serting the names of (or allusions to) those commenting on the text. Ágnes Rapai published a cycle of poems and letters of the (fictitious) lover of the Russian poet Sergei Ésenin, and sometimes in the text itself reflected on the comments concerning her previous posts. Also, she appropriated some photos recommended to her. Mari Falcsik (and others, too) make a wide use of photos appropriated or taken over from other users, and integrate them as a form of commentary into her own poetic texts, thus producing an original "picture book" of some sort - and one can witness the procedure, during which a small series of poems is formed through the discovery or selection of a photo, which is then given a special position (and interpretation) among the poems. And this is Internet literature par excellence. It is highly doubtful that these poems, along with the corresponding photos, will ever be published in book form, and if they were to be published, the experiential process of witnessing the cycles of forming and reforming would be lost.

If, as suggested above, the reader may be part (or at least observer) of a literary text in its very creation, this implies a new experience never to be gotten from traditional literary communication. Even if there is no live interaction, for the reader to be a spectator during the process of creation is a unique literary event.

\section{Dispersion in "Space"}

As has been discussed, a poem can be scattered in time. The time of the reading process can be controlled by giving portions of the text with certain (random or designed) intervals. Cyberspace, however, offers the opportunity to disperse the text in "space." Lines or parts of the poem (or narrative, for that matter) can appear in different "places." Thus, for instance, in the summer of 2010 Ágnes Rapai posted lines of a poem of hers on the Facebook pages of about a dozen "friends", one line for each. One could read the whole poem only if one were "friends" of Ágnes Rapai's friends. This required some work (and the courage to ask some people to be "friends" so that one could get access to the missing line[s]), and one could speculate whether the persons hosting the line of the poem in question had anything to do with that very line. Unlike temporal dispersion of a text, this trick is not impossible to repeat, and you do not have to be online to perceive its upshot. However, the poem presented in this manner is not at all the same as a poem conveyed through conventional channels of communication, in an offline written form. 


\section{Marketing Literature}

As has been suggested, reader-literature encounter has an extended chance on "community sites." People are more likely to read literary texts on the net than irl [in real life]. This includes, in addition to the original and strange cases listed above, the much more traditional forms of literary communication in the medium of Internet communication. These latter forms serve to popularize, circulate, spread (and comment on) the literary text, which, in turn, is a previously written, sometimes already printed (published) work. They are not at all inferior to the more innovative versions, but their objective is clearly different, and the fundamental structure of the reader/writer relation is not changed. However, both presenting the literary work and the literary marketing on the net opens new perspectives, first of all because a huge amount of paratexts are generated, such as authorial statements and pronouncements, ads, and readers' comments, which are present in the printed medium in a more rudimentary way. Furthermore, a sort of intimacy can be regained through the fact that the writer may know his or her readers personally (or at least by name). He or she can react to their comments, and may make their communication interactive.

In his seminal essay of marketing literary works in the cyberspace (http://www.prae.hu/prae/articles.php?type=4\&cat=3\&aid=1326), Dániel Levente Pál mentions some interesting cases, including the launch of a special blog by a publishing house to the PR activities intended to "build up" a new author (by publishing his or her biography, the cover of the book, blurbs, etc.) or even creating a virtual introductory show of the book (via video cameras, SMS's, projectors, net communication, etc.). The possibilities are countless, and it also should be mentioned that the main instrument of both communicating and marketing literary works, literary magazines, are more and more present on the Internet (moreover, some facing extinction in the print world and survive only on the web). Thus an ever growing part of both publication and marketing is continuously moving to the field of digital communication.

\section{Conclusion}

It was not my intention in this paper to suggest that the interesting phenomena listed above (making the presentation of the work temporal, dispersing it spatially, the collective composition of works of literature and interactive creation) will, in themselves, produce aesthetically valuable literature. Nor do I mean to imply that these variations are momentous in the history of literature in general. Emphasis is 
on their potential. If certain traits and procedures, which may now seem accidental or casual, will be iterated several times, if they gain certain rules and frames, then new forms will have the chance to develop, forms that one can call new genres, genres in which, for instance, the temporal evolvement of the work will be the focus, or else the motion between different sites where text dwells. But, more importantly, we cannot foresee the possible new, original and perhaps surprising forms yet to be born, so let us be perceptive and attentive to the new phenomena. ${ }^{7}$

\section{Notes}

1 Iván Horváth, sous la dir. de (1992 [1993]) Répertoire de la poésie hongroise ancienne. Manuel de correction d'erreurs dans la base de données, I-II (Paris: Éditions du Nouvel Objet), $49+808$ pp., assisté par Gabriella H. Hubert, cooperé par Zsuzsa Font, János Herner, Etelka Szőnyi, István Vadai, György Gál (responsable de mathématiques), Tamás Ruttner (responsable d'enregistrement textuel); (version 3.0), MicroCDS/ISIS, 6 disquettes (1992 [1993]) (Paris: Éditions du Nouvel Objet), in Hungarian: A régi magyar vers számitógépes repertóriuma (Répertoire de la poésie hongroise ancienne), 4.0 hálózati változat [Network version 4.0], BRS/Search 'POEM': http://www.iif.hu/db/poem/ (1993); Version 3.1 (CD), abCD, I (1994), fasc. 2; Version 5.0 (internet edition) (2000) http://magyar-irodalom.elte.hu/ repertorium/dokument/index.html (online ed. Róbert Karsai).

2 Balassi Bálint összes versei. Hálózati kritikai kiadás (The Complete Poems of Bálint Balassi. Online Critical Edition) http://magyar-irodalom.elte.hu/gepesk/bbom/cimlap.htm (1998). (Ed. Iván Horváth, Tünde Tóth.)

3 József Attila, Tanulmányok és cikkek, 1923-1937. Kísérleti hálózati kritikai kiadás [Attila József, Studies and Articles, 1923-1937. Experimental Online Critical Edition] http://magyar-irodalom.elte.hu/ja/cimlap.htm/ (1999) (Ed. Iván Horváth).

4 For a full list of Online Critical Editions see http://magyar-irodalom.elte.hu/gepesk/index/.

5 Horváth Iván (2000) 'A legnehezebb kérdés' [The Most Difficult Question], in his Magyarok Bábelben [Hungarians in Babel] (Szeged: JATEPress), 191-201, http://magyarirodalom.elte.hu/babel/3300.htm, http://magyar- irodalom.elte.hu/babel/2130.htm

6 Several issues touched upon above are raised in Dániel Levente Pál (2009) 'Philologia 3.0', in Vilmos Bárdosi (ed.): Quo Vadis Philologia Temporum Nostrorum? (Budapest: Tinta), 219-24.

7 This study is a version of my essay 'Az élő net-irodalom néhány változata' [Some Versions of Living Net-Literature] (2010) http://www.es.hu/index.php?view=doc;26101, Élet és Irodalom Vol. 54, No. 23, 13; an important reply was written by Levente Dániel Pál, 'Élő net-irodalom, kiberfilológia, (ön)marketing' [Living Net-Literature, Cyberphilology, (Self-)Marketing], (2010) http://www.es.hu/?view=doc;26187, Élet és Irodalom Vol. 54, No. 25,2 . 